\title{
Outcomes of women referred for sterilisation
}

\author{
Rebekah A Smith, Elizabeth A Martindale
}

\begin{abstract}
Objective To evaluate whether women referred to a gynaecology clinic requesting sterilisation were receiving appropriate counselling about sterilisation and other forms of long-term contraception, and to determine the proportion of women who ultimately underwent sterilisation.
\end{abstract}

Methods A retrospective audit of 100 women referred requesting sterilisation.

Results $15 \%$ of women referred did not attend the clinic, $54 \%$ had sterilisation and $29 \%$ ultimately chose an alternative method. Alternative forms of contraception discussed were levonorgestrel-releasing intrauterine system $(69 \%)$, vasectomy $(34 \%)$ and subdermal progestogen implants (21\%). At the clinic $70(82 \%)$ women chose sterilisation; however, 15 (21\%) of these women cancelled the operation.

Conclusions Almost half of the women referred for sterilisation did not proceed with it, suggesting that there was insufficient counselling about sterilisation and alternative long-term contraception before referral to the gynaecology clinic and also within the clinic itself.

\section{Key message points}

- One in five women $(21 \%)$ who decided to undergo sterilisation when seen in clinic later changed their minds and cancelled the operation.

- Almost half (46\%) of the women referred for sterilisation did not attend the clinic or opted for alternative methods of long-term contraception.

- Women need appropriate counselling and information on all forms of long-term contraception and the risks of sterilisation before referral and also within gynaecology clinics.
J Fam Plann Reprod Health Care 2006; 32(3): 184-185

(Accepted 16 January 2006)

\section{Maternal and Fetal Health Research Centre, St Mary's Hospital, Manchester, UK \\ Rebekah A Smith, MRCOG, DFFP, Specialist Registrar in Obstetrics and Gynaecology}

\section{Department of Obstetrics and Gynaecology, Queen's Park Hospital, Blackburn, UK \\ Elizabeth A Martindale, MRCOG, MFFP, Consultant Obstetrician and Gynaecologist}

Correspondence to: Dr Rebekah Smith, Maternal and Fetal Health Research Centre, St Mary's Hospital, Hathersage Road, Manchester M13 0JH, UK. E-mail: rasmith@doctors.org.uk

\section{Introduction}

Laparoscopic sterilisation is a common gynaecological procedure in the UK and is seen as a permanent procedure with a quoted lifetime failure rate of 1 in $200 .{ }^{1}$ However, there are now good alternative methods of long-term contraception with comparable or lower failure rates. ${ }^{2}$ Methods such as the levonorgestrel-releasing intrauterine system (IUS) or subdermal progestogen implants (e.g. Implanon ${ }^{\circledR}$ ) have the added advantage of reversibility. There are a significant number of women who express regret following sterilisation, and up to one-third of these women may request reversal of sterilisation ${ }^{3}$ which is expensive and not funded by the National Health Service in many areas of the UK.

This audit was conducted as it was noted that women referred to the gynaecology clinic at our unit requesting sterilisation did not seem to be fully aware of the options for long-term contraception. It also appeared that several women changed their minds about sterilisation in the clinic. Therefore, the objectives of this audit were to evaluate whether women requesting sterilisation were receiving appropriate counselling about sterilisation and other forms of long-term contraception, and to determine the proportion of women who ultimately underwent sterilisation.

\section{Methods}

A retrospective audit was conducted in a sample of 100 women referred to Queens Park Hospital in Blackburn, UK requesting sterilisation between March 2002 and September 2002. The audit standards were the Royal College of Obstetricians and Gynaecologists guidelines on male and female sterilisation. ${ }^{1}$ Case notes were reviewed for details concerning demographic data, referral source, discussion regarding types of long-term contraception, and final outcome in terms of contraception chosen.

\section{Results}

The women were referred from general practitioners (GPs) (93), midwives (5) and the colposcopy clinic (1), with the referral source being unknown in one case. The age range was $24-47$ years, with a mean of 34 years. The parity of women ranged from 0 to 8 , with a parity of 2 being the most common.

Alternative forms of contraception documented to have been discussed were the IUS in 69\% of cases (59 cases), vasectomy in $34 \%$ of cases (29 cases) and Implanon in $21 \%$ of cases (18 cases). In 11 cases (13\%) there was documentation that 'alternatives' had been discussed without specifying which ones.

Of the 85 women seen in clinic, $70(82 \%)$ women chose sterilisation; however, 15 (21\%) of these women then cancelled the operation. After being seen in clinic, $10(12 \%)$ women chose the IUS, one (1\%) woman Implanon, and three $(4 \%)$ women other methods. The remaining woman stated that she had never requested referral for sterilisation!

Overall, for 100 women referred requesting sterilisation, $15 \%$ (95\% CI 8-22) did not attend the clinic, $54 \%$ (95\% CI 44-64) underwent sterilisation and 29\% (95\% CI 20-38) ultimately chose an alternative method.

\section{Discussion}

Almost half of the women referred for sterilisation did not ultimately undergo the procedure. A proportion of these cases were due to non-attendance at the gynaecology clinic, 
which may be due to the women changing their minds or having more time to consider the options for long-term contraception suggested by their GPs. A study by Mattinson and Mansour ${ }^{4}$ assessing a female sterilisation counselling clinic run by family planning-trained staff found a higher rate of non-attendance (32\%) compared to the present study $(15 \%)$. Their patients receive leaflets on sterilisation and other long-term contraception methods prior to their appointments. At the time the present study was conducted our patients did not receive any information prior to their visit. This written information provided in Mattinson and Mansour's study might have helped women to decide on other alternatives and access them from other sources and therefore not attend the clinic.

Overall, 64\% of our women attending the gynaecology clinic underwent sterilisation, which is similar to the figure found by Mattinson and Mansour (61\%). ${ }^{4}$ Of those women attending our clinic, $21 \%$ who initially opted for sterilisation later cancelled their operation. This may suggest that once the women had time to think about the available options they no longer wanted to undergo the sterilisation procedure.

The present study has the disadvantage of being retrospective, and as such relies on the documentation of consultations in case notes. Within the gynaecology clinic not all women were being fully counselled about long-term contraception. Presenting this audit has helped highlight this issue, and in addition the use of proforma sheets or a stamp in case notes can act as an aide memoire.

The sample size in this retrospective study was small due to the accessibility of patient case notes. This limits the conclusions that can be drawn from the present study, but reassuringly the percentage of women who proceeded with sterilisation is similar to that found in the larger study of 226 women conducted by Mattinson and Mansour. ${ }^{4}$

Women need to be appropriately counselled before referral to gynaecology departments, although there will be many women who receive appropriate counselling and are never referred. We are now sending written information on laparoscopic sterilisation and alternative methods of longterm contraception to all women referred for sterilisation prior to their appointment in order that they might consider all the options before making their decision. A re-audit is planned to determine if these interventions improve the counselling of women and increase the proportion of women who ultimately proceed with sterilisation.

Statements on funding and competing interests

Funding. None identified.

Competing interests. None identified.

References

1 Royal College of Obstetricians and Gynaecologists (RCOG). Male and Female Sterilisation (National Evidence-Based Clinical Guideline No. 4). London, UK: RCOG Press, 2004.

2 Guillebaud J. Contraception Today (4th edn). London, UK: Churchill Livingstone, 2000.

3 Hillis SD, Marchbanks PA, Tylor LR, Peterson HB. Poststerilization regret: findings from the United States Collaborative Review of Sterilization. Obstet Gynecol 1999; 93: 889-895.

4 Mattinson A, Mansour D. Female sterilisation: is it what women really want? J Fam Plann Reprod Health Care 2003; 29(3): 136-139.

Editor's Note

Interested readers should note that a Short Communication authored by Mattinson and Mansour (which relates to an earlier article by these same authors cited as Reference 4 by Smith and Martindale) appears in this issue of the Journal on pp. 181-183.

\section{Book Reviews}

Contraception and Contraceptive Use. A Glasier, K Wellings, H Critchley (eds). London, UK: RCOG Press, 2005. ISBN: 1-904752-15-2. Price: $£ 48.00$. Pages: 267 (paperback)

The Royal College of Obstetricians and Gynaecologists (RCOG) Study Groups have been convened for 30 years. Eminent clinicians and scientists are invited to present relevant research and partake in in-depth discussions. The remit for the 49th Study Group was to explore the big picture of contraceptive use and to discuss the demographic, social and behavioural issues affecting it.

There is no questioning, therefore, the authority of the contributors. The book is almost 300 pages long and is divided into three sections: 'The Current Situation', 'Making Things Better' and 'Consensus Views'. The chapters are well set out, evidence-based, and backed with effective tables, figures and graphs.

The first section is the largest, comprising 15 chapters. Personal highlights included Kaye Wellings' overview of NATSAL 2000, Geraldine Barrett's account of developing a British validated measure of unplanned pregnancy, and Ellie Lee's section on late abortion. Diana Mansour writes comprehensive provider's overview, illustrating the astonishing history of contraceptive services in the UK, the impact of the National Sexual Health and HIV Strategy and GMS contract on service provision, the role of the Faculty in developing/maintaining standards and training, and the regulatory bodies concerned with prescribing. Chapters relating to cancer and cardiovascular risks of hormonal contraception and contraception for young people and olde women were less absorbing, having been covered in recent CEU Guidance documents.

The section on 'Making Things Better' included commended chapters on potential targets for female contraception and male contraception Gillian Penney's evidence-based approach to improving patient care links nicely with the work currently undertaken by the Faculty's CEU. Anna Glasier's chapter on improving services highlights the difficulties policymakers and clinicians face trying to reduce rates of unintended pregnancy. Judith Stephenson's review reports that those attempting innovation in delivering sex education face similar challenges.

The final chapter highlights the group's key findings and recommends action points in terms of health policy/education, clinical practice and research. The book ends positively, spurring the reader to embrace the opportunities around fertility control: "What are we going to do? Who is going to make it happen? When will it be done?".

I wore out a previous RCOG Study Group publication when I researched my MD. Similarly, this book is aimed at specialists. I would certainly commend this publication to policymakers, service leaders, career grade/subspecialty trainees, MFFP candidates, educationalists, and those undertaking research in the area of fertility control

Reviewed by Susan Logan, MD, MRCOG, Subspecialty Trainee in Sexual and Reproductive Health Care, Aberdeen, UK

The Art of Sex Coaching: Expanding Your Practice. P Britton. New York, NY: W W Norton and Company, 2005. ISBN: 0-393-70451-3. Price: £19.99. Pages: 218 (hardback)

I have a popular idea of the role of a lifestyle coach and can only wonder at what a sex coach does. Here is an opportunity to find out. Lifestyle coaching is in its infancy in the UK. The American author recommends a model for coaching that concentrates on mind, emotion, body, energy and spirit. Not so very different from the physical, psychological social, and spiritual terms within which we as doctors are meant to frame our diagnoses.

Dr Patti repetitively makes the point that it is coaching and not therapy that she is discussing. One explanation she gives for this is that therapy implies pathology. However, the sexual issues her clients bring to her are very familiar: erectile dysfunction, loss of libido, anorgasmia and others.

Dr Patti uses case vignettes to demonstrate her assessment of her client's problems and her subsequent management. These reported encounters bear little similarity to the Institute of Psychosexual Medicine's use of the patient's narrative and the doctor-patient relationship to help the patient arrive at an understanding.

In order to learn and practise this craft she recommends what feels like an extraordinary list of experiences including sexual field trips. What appealed to me especially out of a wide selection was "Fuck-O-Rama". She describes this as a totalimmersion experience showing over 24 sexually explicit films simultaneously. The purpose of this is to "confront your biases". As doctors we are constantly called on to recognise and leave our biases aside in the area of sexual health. There are other ways of achieving this.

I suspect that when I read the title of this book my biases were alerted, but I did find the approach superficial and lacking in a scientific basis. However, there is a core thread that has value. Sex is not discussed much in society. Some people have difficulties with it and may seek help to change things. For some clients I am sure that their therapeutic encounter with the author was pivotal in achieving change within their sexual lives.

The title suggests the book's intended audience. I believe there are better directions for our professional development than reading this book.

Reviewed by Alex Connan, MRCGP, MIPM, General Practitioner and Family Planning Doctor, Edinburgh, UK 